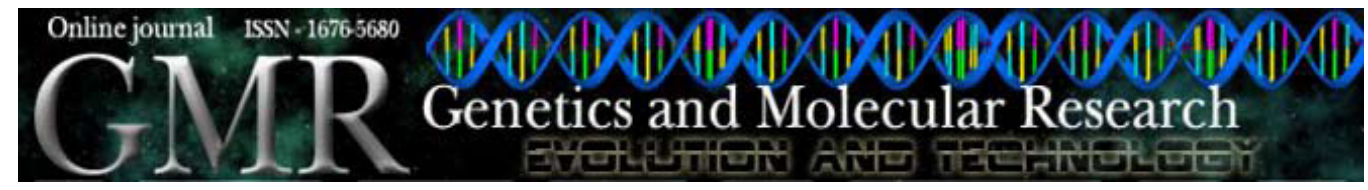

\title{
Amplified fragment length polymorphism analysis of grapevine rootstock genotypes in Turkey
}

\author{
A. Ergüli , S. Aras and G. Söylemezoğlu ${ }^{3}$ \\ Ankara, Turkey \\ Ankara, Turkey \\ Corresponding author: G. Söylemezoğlu \\ E-mail: soylemez@agri.ankara.edu.tr \\ Genet. Mol. Res. 9 (2): 811-819 (2010) \\ Received January 11, 2010 \\ Accepted February 8, 2010 \\ Published May 4, 2010 \\ DOI 10.4238/vol9-2gmr766
}

${ }^{1}$ Biotechnology Institute, Ankara University, Tandoğan, Ankara, Turkey

${ }^{2}$ Department of Biology, Faculty of Science, Ankara University, Tandoğan,

${ }^{3}$ Department of Horticulture, Faculty of Agriculture, Ankara University,

ABSTRACT. Amplified fragment length polymorphism (AFLP) technique was used to assess genetic relationships among 20 grapevine rootstocks in Turkey. Discrimination of the rootstocks with 10 primer combinations yielded 1366 bands on AFLP gels; $65 \%$ of them were polymorphic. The rootstocks revealed two main clusters; one of them comprised two (Malégue and Harmony) and the other 18 genotypes. The Ber x Rip hybrids Cosmo 2 and Cosmo 10 formed a group with a high internal similarity ratio (0.909); they also formed a group with other Ber $x$ Rip hybrids, 5C, 8B, SO4, and 420A Mgt, with a similarity ratio higher than 0.690 (subcluster II). Rootstock 5BB was placed in another subcluster (subcluster III). Among five Ber $x$ Rup rootstocks, 110R-99R (0.853) and 1103P-140Ru (0.837), which were located in different subclusters, formed a dual group, as expected. Rootstock 779P, which had almost 0.800 similarity with the dual group of $110 \mathrm{R}-99 \mathrm{R}$, formed another group. The 44-53 Malégue and Harmony rootstocks formed a group with the lowest similarity ratio (0.668) (subcluster I) and 41B-Fercal formed another dual group with a high similarity ratio (0.813). The 
distinction capacity of single- and double-EcoRI-MseI primers was evaluated; primers $\mathrm{AC} / \mathrm{CTA}, \mathrm{TC} / \mathrm{CAC}, \mathrm{AG} / \mathrm{CTC}$, and $\mathrm{AG} / \mathrm{CAG}$ discriminated the 20 rootstocks, with a similarity value below 0.910 . The best primers for discrimination of rootstock varieties were $\mathrm{AG} /$ CAG and AG/CTC, while the primers TC/CAC and AC/CTA could also be useful for clonal discrimination of genotypes.

Key words: AFLP; Molecular analysis; Grapevine rootstock

\section{INTRODUCTION}

The use of different rootstocks and breeding studies is indispensable when characteristics such as tolerance to abiotic stress conditions are considered, in addition to their use against phylloxera and nematodes. DNA identification and discrimination studies of rootstocks comprising American species and their hybridization within themselves and also with Vitis vinifera are important especially in stages of vegetative propagation and in other biotechnological studies.

In addition to ampelographic studies and isozyme identifications (Walker and Boursiquot, 1992; Walker and Liu, 1995), sequence characterized amplified region (Xu and Bakalinsky, 1996), specific polymerase chain reaction (Bauer and Zyprian, 1997), restriction fragment length polymorphism (Guerra and Meredith, 1995; Bourquin et al., 1995), and especially random amplified polymorphic DNA (RAPD) (This et al., 1997) and simple sequence repeat (SSR) (Sefc et al., 1998; Lin and Walker, 1998) markers have been used in rootstock identification. In these investigations, in addition to determining genetic relationships, the distinctive capacity of markers in rootstocks were defined, and suitable RAPD primers and SSR loci were suggested.

Amplified fragment length polymorphism (AFLP), which scans large areas within the genome, has been used in the discrimination of $V$. vinifera genotypes (clones, synonyms, varietal groups, etc.), yielding a high similarity ratio like many other plant species, but to our knowledge its application for the purpose of rootstock genetic identifications has not been reported.

This research constitutes the first application of the AFLP technique to grapevine rootstocks to reveal the genetic relations of 20 rootstocks using 10 primer combinations. In addition, primers and primer combinations that could be used in rootstock identification, mainly in clonal discrimination, were recorded.

\section{MATERIAL AND METHODS}

\section{Plant material}

The leaves and shoots of 20 rootstock genotypes were obtained from Ankara University Faculty of Agriculture, Kalecik Viticulture Research Station, and Manisa Viticulture Research Institute of the Ministry of Agricultural and Rural Affairs. Rootstocks used for AFLP analysis, their hybridization combinations and sample collections are displayed in Table 1. 
Table 1. Rootstocks used for AFLP analysis, their hybridization combinations and sample collections.

\begin{tabular}{|c|c|c|}
\hline Rootstock & Parentage & Sample collection \\
\hline 1. du lot & Rupestris & 1 \\
\hline 2. Harmony & 1613C x Dog Ridge & 1 \\
\hline 3. Ramsey & Champinii & 1 \\
\hline 4. Dog Ridge & Champinii & 1 \\
\hline 5. Fercal & (berlandieri $\mathrm{x}$ vinifera) × $333 \mathrm{EM}$ & 1 \\
\hline 6. $41 \mathrm{~B}$ & vinifera $\mathrm{x}$ berlandieri & 1 \\
\hline 7. $1613 \mathrm{C}$ & solonis x Othello & 1 \\
\hline 8. $99 \mathrm{R}$ & berlandieri $\mathrm{x}$ rupestris & 1 \\
\hline 9. $110 \mathrm{R}$ & berlandieri $\mathrm{x}$ rupestris & 2 \\
\hline 10. $140 \mathrm{Ru}$ & berlandieri $\mathrm{x}$ rupestris & 1 \\
\hline 11. 1103P & berlandieri $\mathrm{x}$ rupestris & 1 \\
\hline 12. $779 \mathrm{P}$ & berlandieri $\mathrm{x}$ rupestris & 1 \\
\hline 13. $420 \mathrm{~A} \mathrm{Mgt}$ & berlandieri x riparia & 1 \\
\hline 14. SO4 & berlandieri $\mathrm{x}$ riparia & 1 \\
\hline $15.5 \mathrm{C}$ & berlandieri $\mathrm{x}$ riparia & 1 \\
\hline 16. $5 \mathrm{BB}$ & berlandieri $\mathrm{x}$ riparia & 2 \\
\hline 17. $8 \mathrm{~B}$ & berlandieri $\mathrm{x}$ riparia & 1 \\
\hline 18. Cosmo 2 & berlandieri $\mathrm{x}$ riparia & 1 \\
\hline 19. Cosmo 10 & berlandieri $\mathrm{x}$ riparia & 1 \\
\hline 20. 44-53 Malégue & riparia $\times$ (cordifolia $\times$ rupestris $)$ & 1 \\
\hline
\end{tabular}

\section{DNA isolation and AFLP reaction}

DNA was extracted using the procedure described by Lefort et al. (1998). Concentration and purity of the extracted DNA were analyzed using a NanoDrop ${ }^{\circledR}$ ND-1000 spectrophotometer.

The AFLP reaction was performed using a modified procedure from Vos et al. (1995) as previously described by Ergül et al. (2006), and 10 EcoRI/MseI primer combinations were used in the analysis (Table 2).

Table 2. Selected primer combinations and polymorphism rates for AFLP analysis of rootstocks.

\begin{tabular}{|c|c|c|c|c|}
\hline \multicolumn{2}{|c|}{ Primer combination } & \multirow[t]{2}{*}{ Total bands } & \multirow[t]{2}{*}{ Polymorphic bands } & \multirow[t]{2}{*}{$\%$ Polymorphism } \\
\hline$E c o$ RI +2- & MseI +3- & & & \\
\hline $\mathrm{AT}$ & CTC & 142 & 89 & 62.6 \\
\hline \multirow[t]{2}{*}{$\mathrm{AC}$} & CAC & 138 & 89 & 64.4 \\
\hline & CTA & 149 & 89 & 59.7 \\
\hline \multirow[t]{2}{*}{ TG } & $\mathrm{CAC}$ & 135 & 101 & 74.8 \\
\hline & CTC & 106 & 69 & 65.0 \\
\hline \multirow[t]{2}{*}{$\mathrm{TC}$} & CAC & 137 & 81 & 59.1 \\
\hline & CTG & 137 & 75 & 54.7 \\
\hline $\mathrm{TT}$ & CTC & 143 & 104 & 72.7 \\
\hline \multirow[t]{2}{*}{ AG } & CTC & 138 & 106 & 76.8 \\
\hline & CAG & 141 & 98 & 69.5 \\
\hline Total & & 1366 & 901 & 65.9 \\
\hline
\end{tabular}

\section{Data analysis}

The MVSP software package version 3.1 (Kovach, 1999) was used to calculate Jaccard's (1908) similarity coefficients among the genotypes. A dendrogram was constructed using UPGMA (unweighted pair-group method with arithmetic mean). 


\section{RESULTS}

While 10 EcoRI/MseI primers yielded 1366 bands of 50-500 bp, $65 \%$ of these bands (901 bands) were detected as polymorphic and used in the analysis. The ratio of polymorphism did not change significantly according to primer combinations; the range of difference was from $59.1 \%$ (EcoRI-TC/MseI-CAC) to 76.8\% (EcoRI-AG/MseI-CTC) (Table 2). AFLP profiles generated using primer combinations $E c o$ RI-AG/MseI-CTC and EcoRI-AG/MseI-CAG are shown in Figure 1.

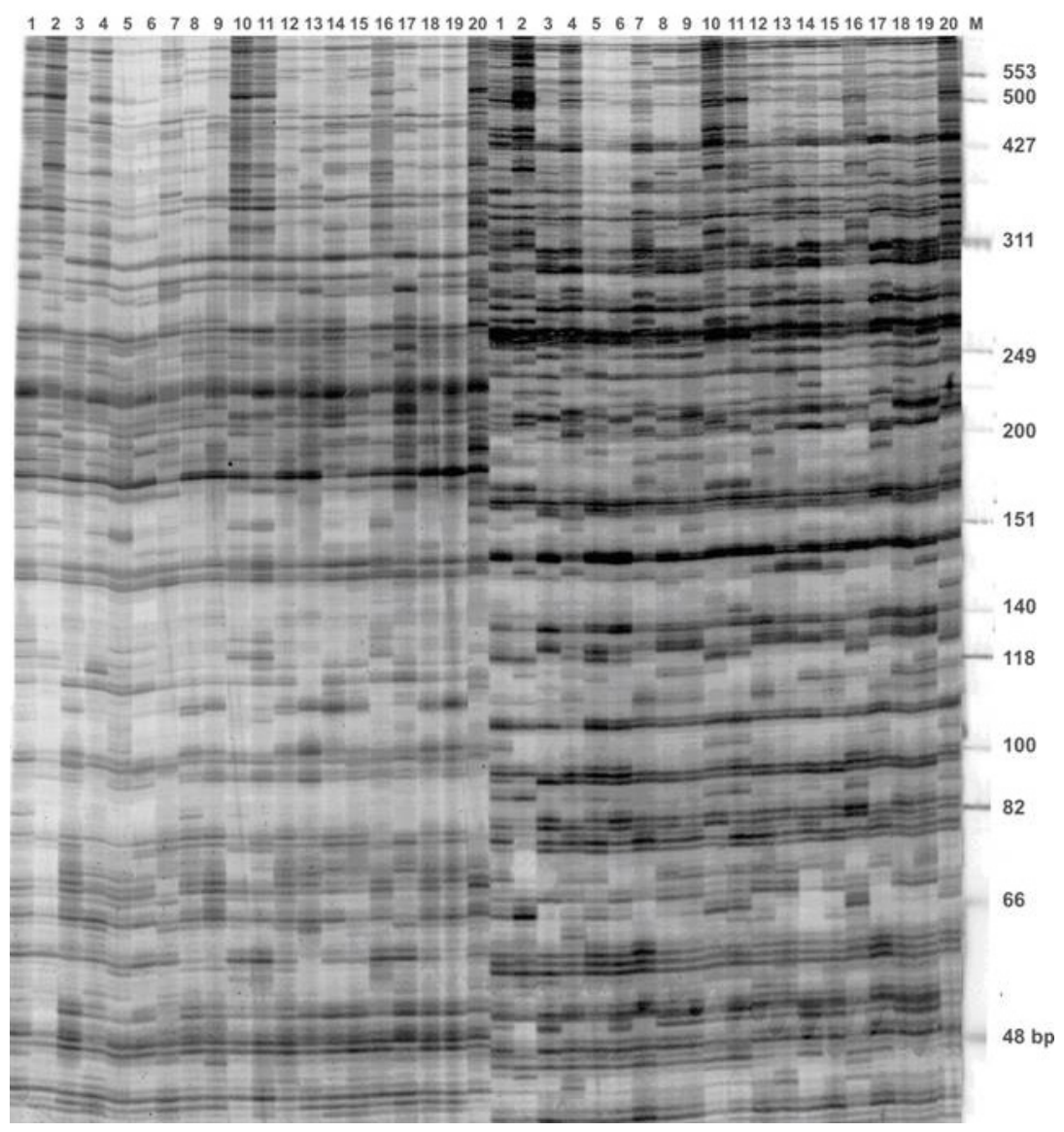

Figure 1. AFLP profiles of rootstocks generated with the selective primer EcoRI-AG/MseI CTC and EcoRI-AG/ MseI-CAG. The names of the accessions have been listed in Table 1 from left to right [1-20], M: ØX174 DNA/ HinfI marker (Promega).

Jaccard genetic similarities between pairs of genotypes in each group can be visualized in the dendrogram obtained from UPGMA analysis (Figure 2). Pairwise similarity ranged from 0.587 to 0.909 , and the lowest genetic similarity was found between 420A Mgt-Harmony, while the highest ratio was obtained between rootstocks Cosmo 2-Cosmo 10. 


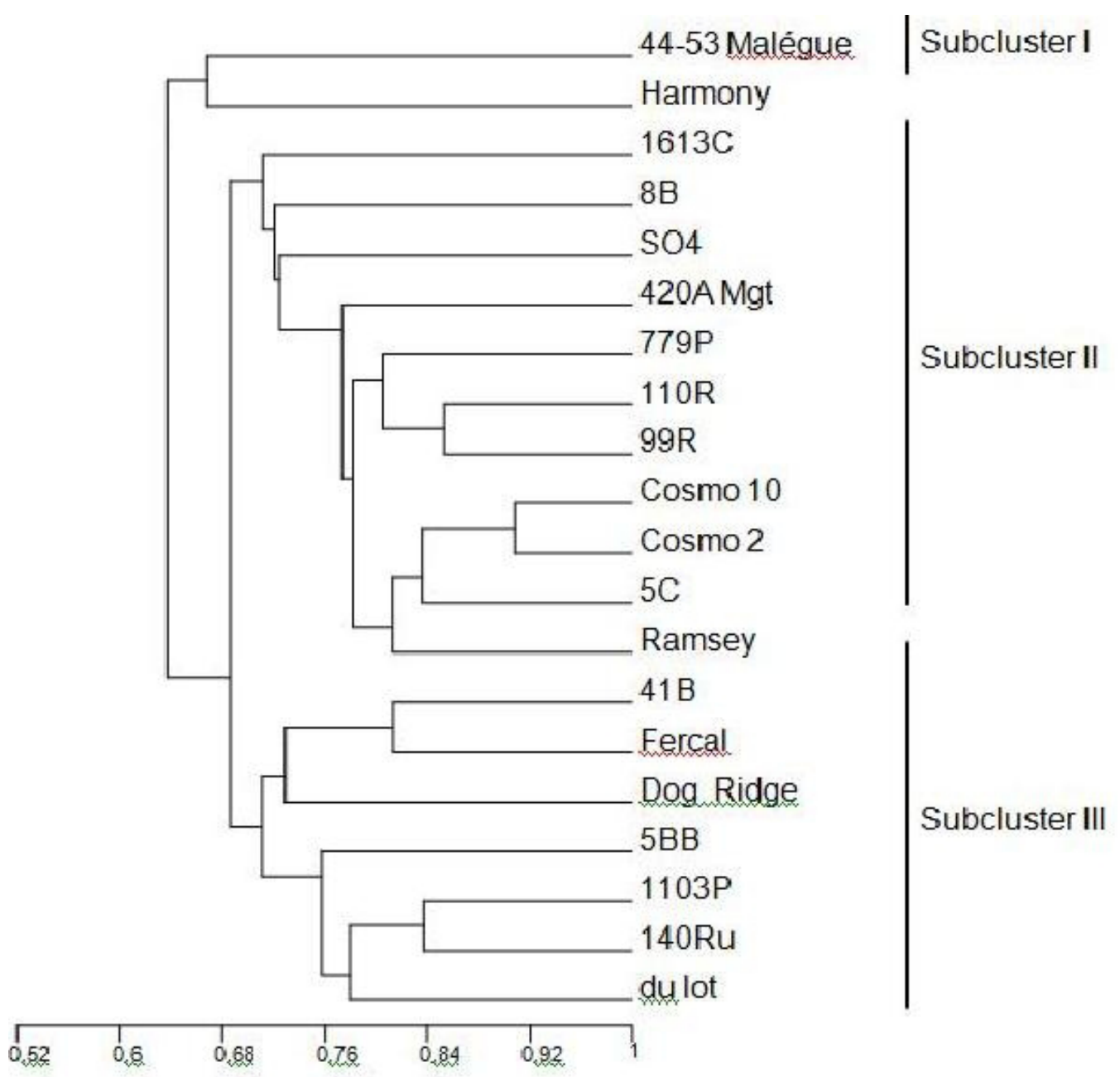

Figure 2. Dendogram showing genetic relationships among 20 rootstock cvs. based on Jaccard's similarity index.

Basically, the dendrogram was separated into two branches comprising 44-53 Malégue-Harmony (subcluster I) and the other 18 genotypes. The 18 genotypes were divided further into two branches comprising 1613C, 8B, SO4, 420A Mgt, 779P, 110R, 99R, Cosmo 10, Cosmo 2, 5C, and Ramsey (subcluster II) and 41B, Fercal, Dog Ridge, 5BB, 1103P, 140Ru, and du lot (subcluster III) (Figure 2).

\section{DISCUSSION}

\section{Genetic relationship and similarity ratio}

When the dendrogram distribution of rootstock genotypes was evaluated on the 
basis of species and hybridization combinations, it was noticed that, while the hybrid of Ber x Rip; Cosmo 2-Cosmo 10 (0.909) formed a group with 5C, rootstocks 8B, SO4, 420A Mgt were grouped with a similarity ratio higher than 0.690 (subcluster II). 5BB, which is commonly used in Turkey and has yielded no genetic variation across nurseries based on RAPD analysis (Ergül and Ağaoğlu, 2001), took part in subcluster III separated from other Ber $x$ Rip rootstocks. When the five Ber $x$ Rup rootstocks were examined, it was seen that 110R-99R (0.853) and 1103P-140Ru (0.837) that were located in different subclusters formed a dual group as expected.

779P, by showing almost 0.800 similarity with the dual group of $110 \mathrm{R}-99 \mathrm{R}$, formed another group (Figure 2). While 44-53 Malégue and Harmony rootstocks constitute a group with the lowest similarity ratio (0.668) (subcluster I) far apart from other genotypes, vinifera $\mathrm{x}$ American hybrid, 41B-Fercal formed another dual group showing a high similarity ratio (0.813). While Ramsey-Dog Ridge (0.794) that took place in the Champini group distributed in different subclusters, rupestris selection du lot, comprised a group with Ber $x$ Rup rootstocks (1103P-140Ru) (subcluster III). 1613C, which manifested single branching, was placed in subcluster II, with the rootstocks $8 \mathrm{~B}, \mathrm{SO} 4,99 \mathrm{R}$, $779 \mathrm{P}$, Cosmo 2, Cosmo 10, and 5C having a similarity ratio higher than 0.700 with these rootstocks.

\section{Distinctive capacity of the AFLP markers for rootstock genotyping}

Although rootstocks have been identified previously by Upadhyay et al. (2007), only 7 (Dog Ridge, 41B, 1613C, 99R, 110R, 1103P, SO4) of the rootstocks used in the present study have been analyzed in the earlier study. In addition, EcoRI primer with $3 \mathrm{nu}-$ cleotides applied in the previous research by Upadhyay et al. (2007) yielded a lower level of polymorphism compared to the EcoRI primer with 2 nucleotides used in this study.

Therefore, the discrimination of commonly used rootstocks in viticulture with a minimum number of primers, which constitutes the basic purpose of this study, was not investigated in previous studies. The EcoRI-MseI primer combinations used in the study, discriminated the 20 rootstocks from each other successfully with a similarity ratio below 0.909. However, in order to display the capacity of AFLP markers and to recommend a minimum primer number for genetic analysis in rootstock discrimination, similarity ratios of single- and double-combination primers were determined. While Cervera et al. (1998) defined the genotypes showing similarity higher than 0.900 as identical, Imazio et al. (2002) identified 0.910 similarity between two different varieties, Pinot noir and Elbing. Also, Fossati et al. (2001) found 0.920 similarity between two different varieties, Rossera and Urban.

When the results of these previous studies and the ratio of 0.909 obtained for Cosmo 2-Cosmo 10 in the present study were taken into consideration, 0.910 was accepted as the upper threshold for the similarity index between genotypes, and the genotypes having values above 0.910 were regarded as "indistinguishable" (Table 3 ).

When Table 3 was evaluated according to this information, it could be seen that $\mathrm{AC} /$ CTA, TC/CAC, AG/CTC, AG/CAG primers could discriminate 20 rootstocks alone with a value below 0.910 . When the other single primers were examined, the primers $\mathrm{AT} / \mathrm{CTC}, \mathrm{AC} /$ CAC, TG/CAC, TG/CTC, TC/CTG, and TT/CTC yielded similarity above 0.910 in the rootstocks Dog Ridge-Fercal, Cosmo 2-Cosmo 10, Cosmo 2-Cosmo 10, Cosmo 2-Cosmo 10, 


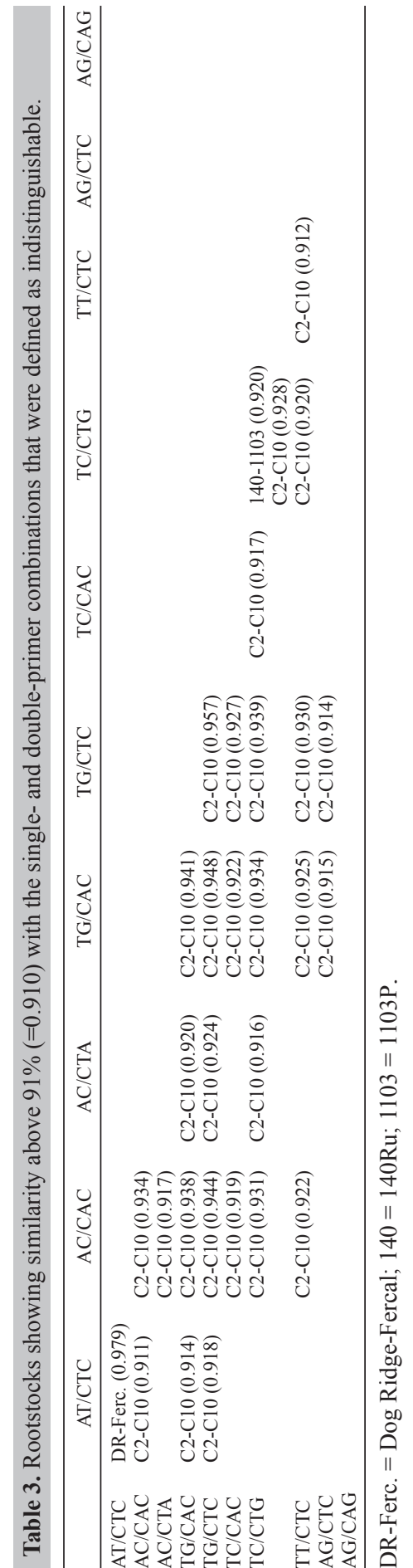


140Ru-1103P, and Cosmo 2-Cosmo 10, respectively, and these primers were considered as "unable to discriminate" for the rootstock combinations.

When the distinctive capacities of two primers were examined among rootstock genotypes, it could be deduced that AC/CTA, TC/CAC, TC/CTG, TT/CTC, AT/CTC; TC/CAC, TT/CTC, AC/CTA; TT/CTC, TC/CAC; except TG/CAC, TG/CTC, other combinations of $\mathrm{AG} / \mathrm{CTC}$ and all combinations of $\mathrm{AG} / \mathrm{CAG}$ primer discriminated 20 rootstocks with a similarity value below 0.910 . When the other 23 dual primer combinations were examined they were regarded as "unable to discriminate" for Cosmo 2-Cosmo 10 rootstocks, but on the other hand, they could be able to discriminate 18 rootstocks. Rootstock numbers, single and double primers able to discriminate are displayed in Table 4.

\begin{tabular}{|c|c|c|c|c|c|c|c|c|c|c|}
\hline & $\mathrm{AT} / \mathrm{CTC}$ & $\mathrm{AC} / \mathrm{CAC}$ & $\mathrm{AC} / \mathrm{CTA}$ & $\mathrm{TG} / \mathrm{CAC}$ & $\mathrm{TG} / \mathrm{CTC}$ & $\mathrm{TC} / \mathrm{CAC}$ & $\mathrm{TC} / \mathrm{CTG}$ & $\mathrm{TT} / \mathrm{CTC}$ & $\mathrm{AG} / \mathrm{CTC}$ & $\mathrm{AG} / \mathrm{CAG}$ \\
\hline $\mathrm{AT} / \mathrm{CTC}$ & 19 & & & & & & & & & \\
\hline $\mathrm{AC} / \mathrm{CAC}$ & 19 & 19 & & & & & & & & \\
\hline $\mathrm{AC} / \mathrm{CTA}$ & 20 & 19 & 20 & & & & & & & \\
\hline TG/CAC & 19 & 19 & 19 & 19 & & & & & & \\
\hline $\mathrm{TG} / \mathrm{CTC}$ & 19 & 19 & 19 & 19 & 19 & & & & & \\
\hline TC/CAC & 20 & 19 & 20 & 19 & 19 & 20 & & & & \\
\hline TC/CTG & 20 & 19 & 19 & 19 & 19 & 19 & 18 & & & \\
\hline TT/CTC & 20 & 19 & 20 & 19 & 19 & 20 & 19 & 19 & & \\
\hline $\mathrm{AG} / \mathrm{CTC}$ & 20 & 20 & 20 & 19 & 19 & 20 & 20 & 20 & 20 & \\
\hline $\mathrm{AG} / \mathrm{CAG}$ & 20 & 20 & 20 & 20 & 20 & 20 & 20 & 20 & 20 & 20 \\
\hline
\end{tabular}

This study aimed to determine the distinctive capacity of AFLP markers in rootstock identification, and as a result, 4 single- and 20 double-primer combinations were shown to be successful in the discrimination of 20 rootstocks (Table 4). If the upper threshold of the similarity ratio, which was kept low and restricted to $91 \%$ ( $=0.910)$ to maintain the easy discrimination of close genotypes (Cosmo 2-Cosmo 10), were increased within certain limits (for example up to $92 \%(=0.920)$ ), the number of primers and primer combinations that could be used in genotype differentiation would also increase.

The results of the present study suggest that AFLP markers, being highly reproducible and efficient in the determination of polymorphism, provide an excellent tool in the discrimination of rootstock genotypes using single- or double-primer combinations. The study also suggests that the primers that could have priority in the identification of rootstock varieties are $\mathrm{AG} / \mathrm{CAG}$ or $\mathrm{AG} / \mathrm{CTC}$, while the primers TC/CAC and AC/CTA could also be used in clonal discrimination of genotypes.

\section{ACKNOWLEDGMENTS}

Research partially supported by the State Planning Organization of Turkey (Project \#2002-K-120130-11) and Ankara University, Institute of Biotechnology (Project\#14 and \#68).

\section{REFERENCES}

Bauer F and Zyprian E (1997). Identification of grapevine rootstocks cv. Börner and differentiation of $125 \mathrm{AA}$ from 5BB and SO4. Vitis 36: 185-189.

Bourquin JC, Otten L and Walter B (1995). PCR-RLFP analysis of Vitis, Ampelopsis and Parthenocissus and its application 
to the identification of rootstocks. Vitis 34: 103-108.

Cervera MT, Cabezas JA, Martínez de Toda F and Martínez-Zapater JM (1998). Application of AFLPs to the characterization of grapevine Vitis vinifera L. genetic resources. A case study with accessions from Rioja (Spain). Theor. Appl. Genet. 97: 51-59.

Ergül A and Agaoglu YS (2001). Molecular similarity analysis of some grapevine rootstocks from different nursery in Turkey. J. Agric. Sci. 7: 141-143.

Ergül A, Kazan K, Aras S, Çevik V, et al. (2006). AFLP analysis of genetic variation within the two economically important Anatolian grapevine (Vitis vinifera L.) varietal groups. Genome 49: 467-475.

Fossati T, Labra M, Castiglione S, Failla O, et al. (2001). The use of AFLP and SSR molecular markers to decipher homonyms and synonyms in grapevine cultivars: the case of the varietal group known as 'Schiave". Theor. Appl. Genet. 102: 200-205.

Guerra B and Meredith CP (1995). Comparison of Vitis berlandieri x Vitis riparia rootstock cultivars by restriction fragment length polymorphism analysis. Vitis 34: 109-112.

Imazio S, Labra M, Grassi F, Winfield M, et al. (2002). Molecular tools for clone identification: the case of the grapevine cultivar 'Traminer'. Plant Breed. 121: 531-535.

Jaccard P (1908). Nouvelles recherches sur la distribution florale. Bull. Soc. Vaud. Sci. Nat. 44: 223-270.

Kovach WL (1999). MVSP - A Multivariate Statistical Package for Windows. Version 3.1. Kovach Computing Services, Pentraeth.

Lefort F, Lally M, Thompson D and Douglas GC (1998). Morphological traits, microsatellite fingerprinting and genetic relatedness of a stand of elite oaks $(Q$. robur L.) at Tullynally, Ireland. Silvae Genet. 47: 257-262.

Lin H and Walker MA (1998). Identifying grape rootstocks with simple sequence repeat (SSR) DNA markers. Am. J. Enol. Vitic. 49: 403-407.

Sefc KM, Regner F, Glossl J and Steinkellner H (1998). Genotyping of grapevine and rootstock cultivars using microsatellite markers. Vitis 37: 15-20.

This P, Cuisset C and Boursiquot JM (1997). Development of stable RAPD markers for the identification of grapevine rootstocks and the analysis of genetic relationships. Am. J. Enol. Vitic. 48: 492-501.

Upadhyay A, Saboji MD, Reddy S, Deokar K, et al. (2007). AFLP and SSR marker analysis of grape rootstocks in Indian grape germplasm. Sci. Horticult. 112: 176-183.

Vos P, Hogers R, Bleeker M, Reijans M, et al. (1995). AFLP: a new technique for DNA fingerprinting. Nucleic Acids Res. 23: 4407-4414.

Walker MA and Boursiquot JM (1992). Ampelographic and isozyme data correcting the misnaming of the grape rootstock SO4 at the University of California, Davis. Am. J. Enol. Vitic. 43: 261-265.

Walker MA and Liu L (1995). The use of isozymes to identify 60 grapevine rootstocks (Vitis spp.). Am. J. Enol. Vitic. 46: 299-305.

Xu H and Bakalinsky AT (1996). Identification of grape (Vitis) rootstocks using sequence characterized amplified region DNA markers. HortScience 31: 267-268. 